\title{
Event Philosophy: Ontology, Relation and Process
}

\author{
Lin Yu \\ Institute of Foreign Linguistics and Applied Linguistics, Henan University, Kaifeng, China \\ Email: yulin@vip.henu.edu.cn
}

How to cite this paper: Yu, L. (2022). Event Philosophy: Ontology, Relation and Process. Advances in Literary Study, 10, 120-127. https://doi.org/10.4236/als.2022.101009

Received: November 29, 2021

Accepted: January 7, 2022

Published: January 10, 2022

Copyright $\odot 2022$ by author(s) and Scientific Research Publishing Inc. This work is licensed under the Creative Commons Attribution International License (CC BY 4.0).

http://creativecommons.org/licenses/by/4.0/

\begin{abstract}
"Event", as a mainstream in contemporary philosophy, remains its hot status in various research areas. Since it has experienced a "linguistic turn" in philosophy, this paper mainly discusses the philosophical development of event ontology, event semantic, event relation and event process from some representative philosophers. The research results indicate that events gradually gained their historical status in relation to substance, and they can be described in a more dynamic and hierarchical way. Furthermore, this paper can also provide philosophical support to the study of corresponding concepts of time and space in literature, nouns and verbs in linguistics.
\end{abstract}

\section{Keywords}

Event Ontology, Event Semantics, Event Relation, Event Process, Event Philosophy

\section{Introduction}

"Event" is a common topic in philosophy, literature, psychology, linguistics, and other fields. The philosophy of event is not particularly new during the long history of human beings from the Ancient Greek, Aristotle, to contemporary thinkers such as Whitehead, Russell, Broad and Quine, the list has had a considerable following. Events, in philosophy, are construed as the changes in the form of obtaining or losing the properties of objects. In other words, events can be conceived as objects in time or objects retaining the properties. Traditionally, philosophers prefer to emphasize the clear-cut boundary between static beings and dynamic events. In contrast, the conventional tendency has been challenged by so-called event process approach or process philosophy. Figuring out different developing stages of event study in philosophy cannot only benefit its ontological research diachronically, but also pave the way for its application in inter-dis- 
ciplinary studies, such as event grammar (Li \& Shen, 2021), event literature (Liu, 2021), and event segmentation or individualization in psychology (Zacks \& Swallow, 2007), etc. With the purpose to provide some philosophical insights of events to its literature and language study in specificity, this paper selects some influential philosophers and their general ideas of event ontology, event semantics, event relation and event process as well in the following four sections, and the last section mainly summarizes the conclusions of this paper.

\section{Aristotle: Event Ontology and Three Types of Events}

"Event" related literature can be traced back to Aristotle in philosophy (Krifka, 1998; Rosen, 1999; Tenny \& Pustejovsky, 2000). Aristotle does not explicitly discuss events in his dichotomous categories of the world. One category is the universal basis of being, namely, "substance", which "is primary in every sense and can exist independently" (Aristotle, 1984: p. 89). Another basic category of being is dependent to "substance", including "quality, quantity, state, relation, action, and motion" (Aristotle, 1941: pp. 35-42; McHenry, 2015: p. 11), from which we can infer that events exist in the dependent category. Aristotle proposes three event types-actuality, action and movement (Rosen, 1999: p. 3). Their definitions are sketched as follows.

"Actuality means the existence of the thing, ... Since of the actions which have a limit none is an end but all are relative to the end, ... For every movement is incomplete-making thin, learning, walking, building; these are movements, and incomplete movements." (Aristotle, 1984: pp. 128-129)

An "actuality" describes an event of state (Rosen, 1999: p. 3). Example [1] is an actuality, and it expresses the state of the Hermes statue that stands in the block of wood. An "action" is an event "with an inherent end" (ibid: 3), which is accomplished immediately. Just as example [2] suggests, when we see something, the process of "we are seeing" and the result of "we have seen" are accomplished at the same time. A "movement" is an event "lacking an inherent terminus" (ibid: 3). In example [3], the process of "we are learning" is durable, and it does not signify the result of "we have learned". In other words, "action" is telic and "movement" is atelic.

[1] A statue of Hermes is in the block of wood.

[2] At the same time we are seeing and have seen.

[3] (We are) leaning. (Aristotle, 1984: pp. 128-129)

When Aristotle's procedure of categories is deduced from the perspective of linguistic forms, these two categories can be equated with the simple terms of nouns and verbs (McHenry, 2015: p. 12). We can infer that Aristotle's three types of the event all pertain to the verbs in linguistics. The linking verb "is" in example [1] indicates the event of state, "see" in example [2] expresses an event of action, and "learn" represents the event of movement.

Even though Aristotle does not directly and explicitly illustrate the concept of 
events, it can be still figured out that he regards actions and movements in the same manner as actualities, that is, the being of substance. In addition, the existence of events is preconditioned on the basis of substance. Correspondingly in linguistics, categories in Aristotle's procedure are deduced from an analysis of linguistics forms that are divided into nouns ("things said without combination") and verbs ("things said in combination"). The nouns as substance are characterized above all as the same as the individual things. In contrast, verbs as events can be conceived as dynamic beings or any changes that they undergo. In short, the latter is subordinate to the former one.

Influenced by Aristotle, Vendler's lexical semantics and Davison's logical semantics open up new venues in studies of events in philosophical linguistics (Tenny \& Pustejovesky, 2000: pp. 3-5; Wu, 2012: p. 511; Li \& Shen, 2021: p. 20).

\section{Vendler: Lexical Semantics of Events}

Vendler $(1957,1967)$ extends Aristotle's three types of the event into four typesstate, activity, achievement, and accomplishment. He classifies events by three binary semantic features, including stative vs. dynamic, durative vs. punctual, and bounded vs. unbounded (or telic vs. atelic) (Mourelatos, 1981: pp. 201-202; Croft, 2012: p. 33). See Table 1 for details.

In Table 1, we can find events of state and movement in Aristotle's classification are in correspondence with events of state and activity in Vendler's classification. For instance, sentence [4] describes the state of $A$ 's love for somebody at any instant time between $t_{1}$ and $t_{2}$, and semantic features of the state event are static, durative and unbounded. In example [5], $A$ was running during the time stretch $t$, thus, it belongs to Vendler's event of activity and Aristotle's event of movement, which is dynamic, durative and unbounded.

[4] A loved somebody from $t_{1}$ to $t_{2}$. (event of state)

[5] A was running at time $t$. (event of activity) (Vendler, 1967: p. 106)

Moreover, Vendler extends Aristotle's event of action into events of achievement and accomplishment. Achievement and accomplishment are both telic or bounded, but the former is punctual and the latter is durable.

[6] A won a race between $t_{1}$ and $t_{2}$. (event of achievement)

[7] A was drawing a circle at $t$. (event of accomplishment) (Vendler, 1967: p. 106)

Table 1. Vendler's four event types with three binary semantic features.

\begin{tabular}{cccc}
\hline Fvent Types & $\begin{array}{c}\text { stative \& } \\
\text { dynamic }\end{array}$ & $\begin{array}{c}\text { durative \& } \\
\text { punctual }\end{array}$ & $\begin{array}{c}\text { bounded \& } \\
\text { unbounded }\end{array}$ \\
\hline State & stative & durative & unbounded \\
Activity & dynamic & durative & unbounded \\
Achievement & dynamic & punctual & bounded \\
Accomplishment & dynamic & durative & bounded \\
\hline
\end{tabular}


In example [6], the race has been set between $t_{1}$ and $t_{2}$, and $A$ won the race at $t_{2}$. Thus, the event of achievement is dynamic, punctual and bounded. Example [7] is an event of accomplishment, and its semantic features are dynamic, durative and bounded, in which $A$ finishes the process of drawing during the time stretch $t$.

Vendler distinguishes objects, events, and facts from a philosophical point of view. An object is in space, and the relationship with time is different from an event, behavior, or process, which is an indirect relationship. Events and their associated expressions are essentially time entities, and events exist indirectly in space. And the truth is neither in time nor in space. The images projected on noun phrases are object nouns, incomplete moving names, and completely moving nouns.

Vendler's four types of verbs play an important role in the academic history of event research. On one side, it is an extension and extension of the classification of verbs (and phrases) such as Aristotle, Ryle, Kenny, etc. On the other hand, it lays the foundation for the in-depth discussion and expansion of many successors. However, Croft (2012: p. 37) criticizes that Vendler's aspectual features of events are classified incompletely, and he proposes some additional event types with various aspectual features, such as "directed activities" and "undirected activities", etc. In addition, Vendler's classification of four event types is also confronted with a serious shortcoming. Only verbs are focused on in terms of events, but the verbs per se cannot "bring us closer to understand how and where in the grammar events are encoded” (Rosen, 1999: p. 7). With regard to events distributed in the whole sentence, Davison's logical semantics studies the compositional properties between events in sentences (Tenny \& Pustejovesky, 2000: p. 3).

\section{Davidson: Logical Semantics of Event Relation}

Within the situation of the mainstream of analytic philosophy, on the one hand followed by the Aristotelian doctrine, some "anti-event" metaphysicians propose to eliminate events completely. Davidson (1980), on the other hand, has claims the status of events taken along with substances (objects) in his mind-body identity thesis and actions related analysis formulated directly in terms of events. In this sense, the significance of events earn its entry to Davidson's (1980: p. 165) event ontology, for he advocates that actions cannot be accounted of explanation or causality without accepting events as individual entities.

Davidson (1967: p. 91) introduces events "as entities about which an indefinite number of things can be said". The event is "a dated, non-recurrent particular" (Davidson, 2001: p. 91), in other words, "no events are identical, no event is ever identical with another" (Davidson, 2001: pp. 137-138). Davidsons's logical semantics in terms of events succeeds in dealing with adverbial modifications of an action sentence.

[8] Jones buttered the toast slowly, deliberately, in a bathroom, with a knife, at midnight. (Davidson, 1967: p. 82) 
Example [8] describes a specific action, which contains five adverbial modifications- "slowly", "deliberately", "in a bathroom", "with a knife", and "at midnight". It can be interpreted as "there is action $\mathrm{x}$ such that Jones did $\mathrm{x}$ slowly, Jones did $\mathrm{x}$ deliberately, Jones did $\mathrm{x}$ in a bathroom, Jones did $\mathrm{x}$ with a knife and Jones did $\mathrm{x}$ at midnight", then an appropriate singular term, event ${ }_{(\mathrm{e})}$, can be used to substitute for " $\mathrm{x}$ ".

[9] a. $\exists$ e (BUTTER (Jones, the toast, e) \& SLOWLY(e) \& WITH(e, a knife)

\& IN (e, the bathroom) \& AT (e, midnight)

b. There was an event, which was a buttering of the toast by Jones, and the event was slowly, and the event was with a knife, and the event was in the bathroom and the event was at midnight. (Kearns, 2011: p. 245)

Example [28] can be transformed into the logical form of example [9]a. In example [9] a, " $\exists e$ " means that it is a set of events that are represented by various linguistic forms. Example [9] b is the interpretation of [9] a in terms of events in " $\exists \mathrm{e}$ ". Not only the adverbial modifications but also the verb complex can be illustrated in terms of Davidson's logical semantics of events.

[10] a. I flew my spaceship to the Morning Star. (Davidson, 1967: p. 91)

b. $\left(\exists \mathrm{e}^{1}\right)$ (Flew (I, my spaceship, e) \& To (the Morning Star, e)). (Davidson,

1967: p. 93)

Example [10] a can be interpreted as two separated events. For instance, in [29] b, the first event ("e") relates to "Flew", and it consists in the fact that "I flew my spaceship"; the second event ("e") pertains to "To", and it resides in the fact that "(my spaceship move) to the Morning Star". From the examples listed above in this section, Davison thus challenges Aristotle's conception of event ontology where substance gains the priority to events. In Davison's analysis of sentences, events are named by gerunds in various grammatical structures and their logical forms as well, which constitute the event structures by their identified and individualized processes.

As Tenny and Pustejovsky (2000: p. 3) indicates, "lexical semanticists must look outward from the verb to the sentence, and logical semanticists must look inward from the sentence to the verb". In other words, the aspectual features of Vendler's lexical semantics may ignore the syntactic components that are not the verbs of sentences; alternatively, the argument linking of Davison's logical semantics cannot elucidate the details of the aspectual features or subevents in verbs or other syntactic components of sentences. For this reason, we find that Whitehead's ontology of the event process can be the most appropriate philosophical background to reveal the essence of event relations.

\section{Whitehead: Event Ontology and Event Process}

Davison's event relation analysis in logics, regarded as "weak view", raises the

${ }^{1}$ Davidson (1967) remains the original form of $\exists x$, since " $x$ " can be substituted by "event", the logical form " $\exists \mathrm{e}$ " is used in this study. 
status of event as equal as objects which is against "anti-event" approach in philosophy. Instead of eliminating events to keep event ontology tidy and even the "weak view", some advocates of "strong view", such as Whitehead, Russel, and Quine, contend in reversion that substance is an unnecessary substratum while events should acquire their the predominant standing for they are concrete or basic particulars in the world (McHenry, 2015: p. 16).

In Whitehead's early researches, he defines an event as "the specific character of place through a period of time" (Whitehead, 1920: p. 52), in which the spatiotemporal property is "an abstraction from the concrete order of events" (Whitehead, 1922: p. 21). Different from Aristotle's dichotomous categories of the world and the predominant status of the substance category, Whitehead regards the world as sets of events, in which "events support objects rather than the other way around" and objects are "relatively monotonous patterns in events" (McHenry, 2015: p. 51). Events have no independent existence, and they blend into each another as a richer event (Whitehead, 1919: p. 74; McHenry, 2015: p. 52).

"In perception, no event exhibits definite spatio-temporal limits. ... The parts of an event are the set of events (excluding itself) which the given event extends over. It is a mistake to conceive an event as the mere logical sum of its parts. ... They are the whole complex of events contained in that event; for example. If $a$ be the given event, and a extends over $b$, and $b$ over $c$, then a extends over $\mathrm{c}$ and both $\mathrm{b}$, and $\mathrm{c}$ are parts of a. Thus, an event has its own substantial unity of being which is not an abstract derivative from logical construction". (Whitehead, 1919: pp. 74-77)

In the description above, the parts of an event can be conceived as a set of events or subevents, and the event is not just the totality of its subevents. In addition, an event together with other events can also constitute a richer event, and they are ordered by the primary relation of "extending over" (McHenry, 2015: p. 52), and the "extending over" is a relation in which "two limited events can have to each other" (Whitehead, 1920: p. 58).

In Whitehead's later researches, he uses the term "event" in a more general sense. "An event is a nexus of actual occasions inter-related in some determine fashion in some extensive quantum", and one actual occasion is "a limiting type of event" (Whitehead, 1929/1978: p. 80). We can find that Whitehead also takes a nexus between events as an event, and he steers his focus on the "process" about how the events are extended over each over. Therefore, based on Whitehead's process philosophy, "anything that appears to exhibit permanence and an abiding structure in nature must be explained in terms of event process" (McHenry, 2015: p. 51).

Whitehead does not conduct any linguistic analysis to his event process, but he considers the meaning of a word as an event (Whitehead, 1929/1978: p. 182).

${ }^{2}$ The limiting type of event is the final real thing of which the world is made up (Whitehead, 1929/1978: p. 18). It contains only one member, and everything else, such as space and time, is built up by abstraction from the concrete basis provided by the actual occasions (McHenry, 2015: p. 55). 
If we apply Whitehead's event process theory to analyze the verb complex in linguistics or literature, we can infer that the processes between events can be interpreted in terms of the principles that constrain the relationship between the subevents in the main verb and the subevents in the satellite, which constitute the verb complex in linguistics.

\section{Conclusion}

Based on the philosophical background, it is clear that events gradually gain their status and become the mainstream in the long history of philosophy, which is also regarded as the basis in the analysis of event semantics, relation and process as well. The main findings can be summarized as follows:

1) In traditional philosophy of events' research (Aristotle time), the substance is the basis of the existence of events, and it remains its predominant status other than events.

2) Followed by Aristotle's doctrine, Vendler and Davison support the "weak view" that event semantics or event relation should be taken into consideration in the analysis of language (verbs or actions in specialty), and events are as equal as or should be taken along with the substance.

3) Different from the "weak view", the "strong view" represented by Whitehead with his event process endows events with priority to substance. In addition, events can be analyzed in a more systemic and hierarchical way.

The study of events and substance in philosophy can also bring penetrating insights to the corresponding time and space in literature, nouns and verbs in linguistics. For instance, Yu (2021) applies the event hierarchies to the analysis action correlating events. Moreover, there are no clear-cut boundaries between those terms across various disciplines.

\section{Funding}

This paper is sponsored by Henan Social Science Foundation project (2019CYY022), entitled "Event Integration Processes and Cognitive Mechanisms of "V1 $+V 2$ " Compound Verbs in Mandarin", Henan Social Science Foundation project (2021CYY031), entitled " $A$ Comparative Study of the Phonetic similarity of the English-Chinese Vocabulary System Based on the Original Root Hypothesis", and Philosophy and Social Science Innovative Team Project of Henan University, entitled "Foreign Language Talents Training Patterns in the New Era" (2019CXTD007).

\section{Conflicts of Interest}

The author declares no conflicts of interest regarding the publication of this paper.

\section{References}

Aristotle (1941). Categories. In R. McKeon (Ed.), The Basic Works of Aristotle (pp. 3590). Random House. 
Aristotle (1984). Metaphysics. In J. Barnes (Ed.), The Complete Works of Aristotle: The Revised Oxford Translation (Vol. 2, pp. 1-205). Princeton University Press.

Croft, W. (2012). Verbs: Aspect and Causal Structure. Oxford University Press. https://doi.org/10.1093/acprof:oso/9780199248582.001.0001

Davidson, D. (1967). The Logic form of Action Sentences. In N. Rescher (Ed.), The Logic of Decision and Action (pp. 81-95). University of Pittsburgh Press.

Davidson, D. (1980). Essays on Actions and Events. Clarendon Press.

Davidson, D. (2001). The Logical Form of Action Sentences. In D. Davidson (Ed.), Essays on Actions and Events (pp. 91-126). Clarendon Press.

https://doi.org/10.1093/0199246270.003.0006

Kearns, K. (2011). Semantics (2nd ed.). Palgrave Macmillan. https://doi.org/10.1007/978-0-230-35609-2

Krifka, M. (1998). The Origins of Telicity. In S. Rothstein (Ed.), Events and Grammar. Studies in Linguistics and Philosophy (Vol. 70, pp. 197-235). Kluwer Academic Publishers. https://doi.org/10.1007/978-94-011-3969-4 9

Li, F., \& Shen, Y. (2021). An Introduction to Event Grammar. Beijing University Press.

Liu, Y. (2021). Event Intellectual History. East China Normal University Press.

McHenry, L. B. (2015). The Event Universe: The Revisionary Metaphysics of Alfred North Whitehead. Edinburgh University Press. https://doi.org/10.3366/edinburgh/9781474400343.001.0001

Mourelatos, A. P. D. (1981). Events, Processes and States. In P. Tedeschi, \& A. Zaenen (Eds.), Syntax and Semantics, Volume 14: Tense and Aspect (pp. 191-212). Academic Press.

Rosen, S. T. (1999). The Syntactic Representation of Linguistic Events. Glot International, 4, 3-11.

Tenny, C., \& Pustejovsky, J. (2000). A History of Events in Linguistic Theory. In C. Tenny, \& J. Pustejovsky (Eds.), Events as Grammatical Objects: The Converging Perspectives of Lexical Semantics and Syntax (pp. 3-37). CSLI Publications.

Vendler, Z. (1957). Verbs and Times. The Philosophical Review, 66, 143-160. https://doi.org/10.2307/2182371

Vendler, Z. (1967). Verbs and Times. In Linguistics in Philosophy (pp. 97-121). Cornell University Press.

Whitehead, A. N. (1919). An Enquiry Concerning the Principles of Natural Knowledge. Cambridge University Press.

Whitehead, A. N. (1920). The Concept of Nature. Cambridge University Press.

Whitehead, A. N. (1922). The Principle of Relativity with Applications to Physical Science. Cambridge University Press.

Whitehead, A. N. (1929/1978). Process and Reality: An Essay in Cosmology (Corrected Edition). The Free Press.

Wu, G. (2012). Process = Event + Use. Foreign Language Teaching and Research, No. 4, 510-522.

Yu, L. (2021). An Event Integration Approach to Lexicalizations of Action Correlating Events-A Case Study of "V + Dào" Construction in Mandarin. Open Journal of Modern Linguistics, 11, 335-360. https://doi.org/10.4236/ojml.2021.113027

Zacks, J. M., \& Swallow, K. M. (2007). Event Segmentation. Current Directions in Psychological Science, 16, 80-84. https://doi.org/10.1111/j.1467-8721.2007.00480.x 